\title{
PNL Y LOS BENEFICIOS DE SU APLICACIÓN POR LOS PROFESORES DE D.A.C.E.A.
}

\author{
María Cruz Cuevas Alvarez*, Oscar Domínguez Cruz**, Fanny Columba Camarillo Casanova**
}

\author{
Cuevas-Alvarez M.C., Domínguez-Cruz O., Camarillo- \\ Casanova F.C. PNL y los beneficios de su aplicación por \\ los profesores de D.A.C.E.A. Hitos de Ciencias \\ Económico Administrativas \\ 2014;20 (56): 33-44.
}

\section{RESUMEN}

El ensayo pretende difundir la importancia sobre conocer los estilos de aprendizaje que se tienen en las aulas, de cómo mejorar nuestras habilidades de comunicación y que esta sea asertiva; es decir, entender mejor a los alumnos, la manera en qué ellos aprenden y que lo presentado en clase sea recibido favorablemente al receptor por el canal de percepción adecuado. Se propone como estrategia de carácter novedoso a la Programación Neurolingüística (PNL) en nuestras aulas. PNL es una herramienta útil para el docente, ya que brinda resultados casi inmediatos en el proceso enseñanza-aprendizaje, debido a que es un enfoque práctico, dinámico y funcional, que además permite poder realizar actividades exitosas, entretenidas y motivadoras. Con mayor alcance toda vez que permite abarcar a los tres tipos de estilos de aprendizaje (percepciones sensoriales) que surgen a partir de las investigaciones de Richard Bandler y John Grinder (creadores) en 1985.

En lo que al lenguaje corporal se refiere, se sugieren movimientos corporales que deben evitarse en clase para tener una mejor relación alumno-maestro, a modo de crear un ambiente académico armónico y agradable, y que el alumno se sienta con la confianza suficiente de acercarse al profesor y aclarar sus dudas en clase, en lugar de quedarse con ellas durante todo el parcial, semestre o de por vida.

Finalmente, recordar que no todos los alumnos aprenden de la misma manera, ni a como los maestros
Cuevas-Alvarez M.C., Domínguez-Cruz O., CamarilloCasanova F.C. NLP (Neurolinguistic programming) and the benefits of its application by the professors of the D.A.C.E.A. Hitos de Ciencias Económico Administrativas 2014;20 (56): 33-44.

\section{ABSTRACT}

This essay pretends to spread the importance of being aware of the different learning styles that we can find in our classrooms, knowing how to improve our communication skills, and how to become assertive in our communication to understand our students better, know the manner they learn, and make it possible that what is presented in class can favorably be perceived by the receiver through the appropriate perception channel. This essays suggests to apply Neurolinguistic Programming (NLP) in our classrooms, as an innovative strategy. NLP is a useful tool for teachers as it provides almost immediate results in the teaching-learning process due to its practical, dynamic and functional approach, which also allows to perform successful, entertaining and motivating activities. With extended range because it covers the three types of learning styles (sensory perceptions) arising from the research done by Richard Bandler and John Grinder (creators) in 1985.

Regarding the body language, it is suggested to avoid some body movements in class in order to have a better teacher-student relationship, and so creating a harmonic and pleasant academic environment that makes students feel confident enough to approach to the teacher and ask questions concerning the class or doubts they may have, instead of not doing so and keeping those questions with themselves during the partial, the semester, or even for the rest of their whole life.

\footnotetext{
* Profesora-Investigadora. División Académica de Ciencias Económico Administrativas (DACEA). Universidad Juárez Autónoma de Tabasco (UJAT).

** Profesor-Investigador. DACEA-UJAT.

${ }^{* * \star}$ Pofesora-Investigadora. Centro de Enseñanza de Lenguas Extranjeras (CELE).
} 
lo hacemos, sino es cuestión de buscar el punto medio para que la información dada en clase llegue eficientemente a través de los canales de percepción apropiados. Además de que se aprenda a leer el lenguaje corporal de nuestros educandos e identificar casi de manera inmediata si realmente están entendiendo, si los estamos aburriendo, si definitivamente no tenemos su atención y por eso su atención está dispersa.

Al estar consciente de que ésta herramienta nos va a permitir tener un mejor acercamiento, podremos tener clases más significativas, con mayor aprovechamiento de los tiempos y de los recursos que tengamos por ende, poder cumplir en casi su totalidad con lo planteado y con los objetivos de aprendizaje propuestos en nuestros planes de trabajo.
Finally we must remember that not all students learn in the same way or as the teachers do. It's just a matter of searching the midpoint to make that the information provided in class reaches the students efficiently by using the proper perception channels. Furthermore, the teachers must learn to read the body language of their students to identify almost immediately if the students are really understanding or not, if the teacher is making the students get bored, or if the teacher definitely does not have the students' attention and so their attention is scattered.

Being aware that this tool will allow us have a better approach to our students, we can conclude that our classes will be more meaningful, with a better use of the time and the resources, and so, we will accomplish almost entirely the learning goals proposed in our work plans.
Palabras clave: Neurolingüistica. Docente. Funcional. Herramienta.
Key words: Neurolinguistic Programming. Teacher/Professor. Functional. Tool.

DIRECCIÓN PARA RECIBIR CORRESPONDENCIA:Correo electrónico:maria.cuevas@ujat.mx

«El ser humano absorbe y guarda en el inconsciente toda la información a la que ha tenido acceso. Esta información es filtrada a través de su pensamiento, pasando por su sistema neuronal y formando programaciones, las cuales forman creencias que lo conducirán y lo guiarán durante toda su vida. El ser humano es producto de sus pensamientos, acerca de lo vivido y experimentado.» (Armas, Von Ruster, 2009)

a Programación Neurolingüística surge a partir de las investigaciones de Richard Bandler y John Grinder. Bandler estudió filosofía y psicología en la Universidad de California y una maestría en psicología de la Universidad de San Francisco. Grinder estudió psicología en la Universidad de San Francisco, así como también un doctorado en Lingüística en la Universidad de California.

Ambos estudiantes estaban interesados en saber por qué los tratamientos de los terapeutas Virginia Satir, Milton Erickson y Fritz Perls, tenían mejores y mayores resultados comparados con los de otros colegas.

Al término de sus observaciones, ambos llegaron a la conclusión de que el éxito de sus tratamientos residía en emplear procedimientos y patrones de comunicación específicos. «Basándose en dichas estrategias, Bandler y Grinder elaboraron un sistema cuya eficiencia ha podido contrastarse a lo largo de los años, como sistema genérico de aprendizaje o como terapia. Lo denominaron Programación Neurolingüística o PNL» (Mohl, 2006).

«PNL es un modelo, por medio del cual se experimenta el mundo a través de los cinco sentidos" (Bavister, Vickers, 2005), propone herramientas valiosas para dar a los alumnos una educación personalizada y eficiente, viéndolos como individuos más que números en una lista y hacerles llegar la información que se requiere de una manera efectiva.

PNL significa Programación Neurolingüística y de acuerdo a los creadores, Programación se refiere a nuestra aptitud para producir y aplicar programas de comportamiento; Neuro se refiere a las percepciones sensoriales que determinan nuestro estado emocional subjetivo; y Lingüístico se refiere a los medios de comunicación humana, tanto verbal como no verbal.

Para comprender cómo se da el proceso de cambio, se puede imaginar a la persona introduciendo datos en una computadora (cerebro) que es la que procesa, almacena y actualiza cuando las circunstancias lo requieren. Los datos son las experiencias sensoriales (lo que se oye, siente, palpa, saborea, ve). Cuando se necesita decidir sobre cómo actuar ante determinada situación, los datos se actualizan y se antepone el que decidirá cómo tomar la decisión. La PNL parte de una experiencia sensorial específica almacenada en el cerebro, lo importante para trabajar con ella, es conocer la 
estructura y las condiciones en las que se procesó y almacenó la experiencia.

«PNL ofrece numerosas y distintas estrategias de aprendizaje, concebidas especialmente para alcanzar ciertos objetivos y para enfrentarse a determinadas estructuras problemáticas» (Mohl, 2006). Una de las herramientas principales que nos presenta la PNL para manejar en la educación escolar, es el conocimiento de los sistemas representacionales, básicamente para saber por dónde le llega la información al alumno; esto quiere decir cuál es su principal canal de acceso con el exterior.

La PNL se constituye como una significativa y valiosa herramienta para garantizar el desarrollo efectivo de la gestión del conocimiento, que estudia cómo organizamos mentalmente nuestras experiencias sensoriales, emocionales, lingüísticas y de qué manera nos influyen, al mismo tiempo que ofrece técnicas para cambiar conductas o sentimientos no deseados y desarrollar una capacidad de comunicación personal y eficaz. Dicho de otra forma, la PNL interviene en el conocimiento para crear mapas mentales para el rediseño de personas y organizaciones; de esta manera, es posible concluir que a través de la utilización de la PNL los miembros de una organización pueden desarrollar sus competencias al mismo tiempo que cuentan con una guía para realizar de forma óptima su trabajo en la organización, así como al coadyuvar a la organización y a sus integrantes en la capacidad para aprender.

\section{CARACTERÍSTICAS DE LA PNL:}

1. Tiene la habilidad de ayudar al ser humano a crecer, trayendo como resultado una mejor calidad de vida.

2. Presenta un enfoque práctico y potente para lograr cambios personales, debido a que posee una serie de técnicas que se asocian entre sí para lograr una conducta que se quiere adquirir.

3. Se concibe como una poderosa herramienta de comunicación, influencia y persuasión, puesto que, a través del proceso de comunicación se puede dirigir el cerebro para lograr resultados óptimos.

De acuerdo con Grinder y Bandler, descubrieron que los procesos mentales tienen tres claves de acceso a ellos, las cuales utilizan todas las personas al accesar o emitir información a otros y están íntimamente ligadas con los cinco sentidos. Ellos las clasificaron de la siguiente manera:
Estilos de aprendizaje: Visual (vista), auditivo (oído) y kinestésico (olfato, gusto, tacto).

Aplicando este enfoque a nuestro quehacer cotidiano, se puede decir que existen 3 tipos de alumnos (tres estilos de aprendizaje): los visuales, los auditivos y los kinestésicos.

Los alumnos visuales aprenden por medio de cualquier representación con imágenes, íconos o símbolos; los auditivos son los tipos de alumnos que, a diferencia de los visuales, aprenden por medio de sonidos o mensaje hablado, únicamente necesitan escuchar sin necesidad de ver, tal vez recuerden a algún alumno el cual en apariencia no esté prestando atención porque no voltea ni al pizarrón ni al profesor, pero cuando le hacen una pregunta responde y éste a la vez está tomando notas; y finalmente, se encuentran los alumnos kinestésicos, son aquellas que aprenden por medio del olfato, gusto y tacto, son los que necesitan realizar físicamente una actividad para poder aprender.

"Una de las cosas sistémicas que Erickson y Satir y muchos otros terapeutas efectivos hacen, es percatarse inconscientemente de cómo piensa la otra persona, a la que le están hablando y utilizar esta información en modos diferentes» (Grinder, Bandler, 2000).

Para poder comprender mejor a cada tipo de estilo, la tabla 1 presenta el comportamiento que el alumno tiene según el sistema de representación preferido (Burón, 1996).

Esta información debe considerarse importante para los profesores de DACEA y tenerla presente al momento de realizar una planeación de clase, en base a nuestros tres diferentes tipos de alumnos y no caer en concepciones equivocadas, prejuicios o etiquetas que muchas veces se hacen con los alumnos de acuerdo a lo que observamos en la primer semana de clase o por los comentarios de otros profesores sobre algún alumno en particular. Deben tomarse encuenta las ideas propias y percepciones según los hechos y experiencia propia; así mismo, utilizar técnicas de enseñanza que involucren a cualquiera de nuestros tres tipos de alumnos, esta es una forma de asegurarnos de que la información presentada llegue al receptor de manera más eficiente y segura. "Si quieres resultados diferentes, haz cosas diferentes» (Armas, Von Ruster, 2009).

Así mismo, se debe aprender a utilizar el canal y lenguaje correcto para que la información llegue a cada uno de los alumnos, es parte de saber usar todos los sistemas representacionales con términos visuales, auditivos y sensoriales. Frases tales como «lo ven claro» (visual) «quiero decir esto bien alto y claro» (auditivo), «siento 
Tabla 1

El comportamiento segun el sistema de representación preferido

\begin{tabular}{|c|c|c|c|}
\hline & Visual & Auditivo & Kinestésico \\
\hline CONDUCTA & $\begin{array}{l}\text { Preocupado por su aspecto. } \\
\text { Voz aguda, barbilla levantada } \\
\text { Se le ven las emociones en la } \\
\text { cara. }\end{array}$ & $\begin{array}{l}\text { Habla solo, se distrae fácilmente, } \\
\text { mueve los labios al leer, } \\
\text { facilidad de palabra, no le } \\
\text { preocupa especialmente su } \\
\text { aspecto. } \\
\text { Monopoliza la conversación. } \\
\text { Le gusta la música, modula el } \\
\text { tono y timbre de voz y expresa } \\
\text { sus emociones verbalmente. }\end{array}$ & $\begin{array}{l}\text { Responde a las muestras } \\
\text { físicas de cariño, le gusta } \\
\text { tocarlo todo, se mueve y } \\
\text { gesticula mucho. } \\
\text { Sale bien arreglado de } \\
\text { casa, pero en seguida se } \\
\text { arruga, porque no para. } \\
\text { Tono de voz más bajo, pero } \\
\text { habla alto, con la barbilla } \\
\text { hacia abajo y expresa sus } \\
\text { emociones con } \\
\text { movimientos. }\end{array}$ \\
\hline LECTURA & $\begin{array}{l}\text { Le gustan las descripciones, a } \\
\text { veces se queda con la mirada } \\
\text { pérdida, imaginándose la } \\
\text { escena. }\end{array}$ & $\begin{array}{l}\text { Le gustan los diálogos y las } \\
\text { obras de teatro, evita las } \\
\text { descripciones largas, mueve los } \\
\text { labios y no se fija en las } \\
\text { ilustraciones }\end{array}$ & $\begin{array}{l}\text { Le gustan las historias de } \\
\text { acción, se mueve al leer. } \\
\text { No es un gran lector. }\end{array}$ \\
\hline MEMORIA & $\begin{array}{l}\text { Recuerda lo que ve, por } \\
\text { ejemplo las caras, pero no los } \\
\text { nombres. }\end{array}$ & $\begin{array}{l}\text { Recuerda lo que oye. Por } \\
\text { ejemplo, los nombres, pero no } \\
\text { las caras. }\end{array}$ & $\begin{array}{l}\text { Recuerda lo que hizo, o la } \\
\text { impresión general que eso } \\
\text { le causo, pero no los } \\
\text { detalles. }\end{array}$ \\
\hline $\begin{array}{l}\text { ALMACENA } \\
\text { LA }\end{array}$ & $\begin{array}{l}\text { Rápidamente y en cualquier } \\
\text { orden. }\end{array}$ & $\begin{array}{l}\text { De manera secuencial y por } \\
\text { bloques enteros (por lo que se } \\
\text { pierde si le preguntas por un }\end{array}$ & $\begin{array}{l}\text { Mediante la "memoria } \\
\text { muscular". }\end{array}$ \\
\hline INFORMACIÓN & & $\begin{array}{l}\text { elemento aislado o si le cambias } \\
\text { el orden de las preguntas. }\end{array}$ & \\
\hline COMUNICACIÓN & $\begin{array}{l}\text { Se impacienta si tiene que } \\
\text { escuchar mucho rato seguido. } \\
\text { Utiliza palabras como "ver, } \\
\text { aspecto..." }\end{array}$ & $\begin{array}{l}\text { Le gusta escuchar, pero tiene } \\
\text { que hablar ya. Hace largas y } \\
\text { repetitivas descripciones. Utiliza } \\
\text { palabras como "sonar, ruido." }\end{array}$ & $\begin{array}{l}\text { Gesticula al hablar. No } \\
\text { escucha bien. Se acerca } \\
\text { mucho a su interlocutor, se } \\
\text { aburre en seguida. Utiliza } \\
\text { palabras como "tomar, } \\
\text { impresión...". }\end{array}$ \\
\hline SE DISTRAE & $\begin{array}{l}\text { Cuando hay movimiento o } \\
\text { desorden visual, sin embargo } \\
\text { el ruido no le molesta } \\
\text { demasiado. }\end{array}$ & Cuando hay ruido. & $\begin{array}{l}\text { Cuando las explicaciones } \\
\text { son básicamente auditivas } \\
\text { o visuales y no le involucran } \\
\text { de alguna forma. }\end{array}$ \\
\hline
\end{tabular}

Nota: Elaborado con base en Burón, J. (1996). Enseñar a aprender. Introducción a la metacognición.

lo que me quieres decir» (kinestésico), sólo por mencionar unas cuántas frases.

El buen uso del lenguaje incluye el hablar siempre de lo que se pretende y se quiere lograr y evitar utilizar frases que ilustran lo que no se quiere. He aquí un ejemplo: «Recuerden traer mañana su tarea» en lugar de decir «no se les vaya a olvidar su tarea mañana».
Los alumnos denominados y etiquetados «problema», generalmente son la causa de una educación no personalizada, esto quiere decir que no está en su idioma o mejor dicho en su sistema representacional y que de alguna manera no logra captar su atención, no quiere decir que no le interese.

Este tipo de alumnos suelen ser sensoriales. El problema aquí no es del alumno, sino del maestro que 
se empeña en dar la información normalmente por los canales visual y auditivo generalmente, dejando fuera a los alumnos sensoriales. Ejemplo de cómo dar una clase son los museos interactivos para alumnos donde se despiertan los cinco sentidos; asimismo, PNL tiene técnicas específicas para lograrlo también.

Otra técnica muy eficiente para que el alumno esté dispuesto a aprender, es enseñarlo a respirar abdominalmente para oxigenarse al entrar a clases y en los momentos que el maestro detecte cansancio en el grupo; el respirar profundamente de esta manera sitúa al alumno y también al maestro en el aquí y el ahora, siendo más difícil que la atención del alumno se disperse; el mover a los alumnos mediante algún ejercicio también es de gran ayuda (Armas, Von Ruster, 2009).

\section{Lenguaje corporal y verbal}

De acuerdo a PNL, el $90 \%$ de nuestra comunicación es corporal, y el $10 \%$ restante es verbal (O'Connor, Mcdermott, 1997). Lo que quiere decir que el alumno al momento de preguntarle si comprendió, él va a responder sí, aunque todo su cuerpo me está diciendo exactamente lo contrario, y este tipo de observación se denomina saber leer al alumno. El maestro debe aprender a «leer» a sus alumnos a través del lenguaje corporal, es imposible que un alumno que llegue a clases con un problema emocional encima, ponga atención y se desempeñe como los otros compañeros de clase, sin que antes se le atienda. Por eso el manejo de las claves oculares, así como de la fisiología son de gran ayuda dentro de la educación.

A pesar de que la comunicación verbal es mínima, también tiene un rol muy importante, ya que el lenguaje es muy poderoso porque afecta directamente nuestros pensamientos, los cuales están ligados a nuestras emociones. Si alguien le dijera a otra persona: «Todo lo haces mal», "siempre te equivocas» 0 «no sirves para nada», la persona automáticamente construirá una imagen suya haciendo las cosas mal, equivocándose y que no sirve para nada, ya que se le programó para ello con ese tipo de comentario y por ende tendrá una repercusión en sus emociones. Estas emociones negativas afectarán su ánimo, su autoestima y sus capacidades y después de todo esto finalmente se creerá que todo lo hace mal, que siempre se equivoca y que no sirve para nada.

Hay que evitar los comentarios fuera de lugar; es decir, que no vienen al caso, que se consideren sarcásticos y/o burlones, aunque para nosotros sean preguntas 0 situaciones obvias, simplemente responder lo que se tenga que responder. «Si está comprobado que las plantas respondan a buenos tratos, palabras suaves e incluso a la música melódica, ¿cómo responderá un ser humano ante lo mismo?» (Armas, Von Ruster, 2009).

Ejemplo 1:

Alumno: ¿Profesor, disculpe ya pasó lista?

Profesor: Pues en qué planeta vive / A qué viene a la escuela / ¿Qué no sabe qué hora es?

Apropiadamente:

Sí, acabo de terminar / Todavía no / En un momento más.

\section{Ejemplo 2:}

Alumno: Profesor, ¿por qué tengo 5 en el parcial?

Profesor: Yo no invento calificaciones / No lo tiene de a gratis / No por nada tiene 5 / Usted debe de saber por qué.

\section{Apropiadamente:}

Si me permite, en un momento revisamos por qué / Si gusta lo revisamos al final de la clase / Permítame sacar mi registro y juntos veremos por qué

\section{Ejemplo 3:}

Alumno: Profesor, ¿no recuerdo cuál es la fecha de entrega del trabajo?

Profesor: Ya di fecha y no voy a repetir / Ese es su problema / ¿Tienes manos? Pues anote / ¿Tengo facha de asistente?

Apropiadamente:

*A modo también de devolver un poco la responsabilidad al alumno de anotar o investigar por sí sólo antes de acudir al profesor, podríamos decirle: Mire, no tengo a la mano la información. Pregunte mientras con sus compañeros, si aún no la obtiene, se la puedo proporcionar más tarde./ Permítame revisar mi agenda, de memoria al momento, no lo recuerdo.

Este tipo de respuestas en esas situaciones, dan resultados positivos, en primera el alumno no ve al profesor como un inflexible, neurasténico ni malhumorado, sino como una persona con la cual se puede hablar, puede haber acercamiento y permite que haya confianza para preguntar sobre cosas de clase comunes y obvias, que a la vez permitirá que cuando el alumno tenga duda sobre un tema, lo haga con la confianza de que el profesor va responder a sus preguntas de manera agradable, atenta y paciente.

«Como seres humanos tenemos la posibilidad de elegir. Podemos elegir qué pensamos y qué decimos" (Grinder, Bandler, 2000). Con la ayuda de PNL es posible ser más conscientes de lo que ocurre en nuestra mente y darnos cuenta del daño que nos causamos y causamos a los demás. Con PNL es relativamente fácil iniciar un 
aprendizaje más positivo y reentrenar nuestra mente para así desencadenar emociones más alentadoras.

«El maestro cercano, eficiente, el mejor de los maestros es el maestro que logra estar con sus alumnos, que aprende a ser con ellos y a través de ellos, y PNL proporciona las herramientas para elaborar una educación donde cualquier tipo de alumno pueda aprender rápida y fácilmente y donde el maestro pueda fluir» (Armas, Von Ruster, 2009).

En la tabla 2, PNL sugiere evitar las siguientes acciones que tienen que ver con nuestro lenguaje corporal y como lo traduce la persona que nos ve (Ferrari, 2008).
En la tabla 3, se encuentran las sugerencias sobre lo que sí debemos de procurar hacer y el significado que esas acciones recomendadas tienen (Ferrari, 2008).

De acuerdo con los diferentes estilos de aprendizaje que existen en el aula, se pueden realizar actividades con las siguientes recomendaciones:

Visual: Una persona orientada visualmente utiliza principalmente sus ojos para percibir el mundo que lo rodea, y utiliza imágenes visuales para recordar y pensar. El alumno con un canal visual aprende con colores estímulos visuales: colores brillantes, gráficas, mapas, organizadores de información: cuadros sinópticos, tablas comparativas, mapas conceptuales, mapas mentales, cuadros sinópticos y diagramas de flujo.

Tabla 2

Lenguaje corporal inapropiado y significado

\begin{tabular}{|c|c|}
\hline Lenguaje Corporal & Significado \\
\hline Entrelazar los dedos & Autoridad \\
\hline Dar un tirón al oído & Inseguridad \\
\hline Mirar hacia abajo & No creer en lo que se escucha \\
\hline Frotarse las manos & Impaciencia \\
\hline Apretarse la nariz & Evaluación negativa \\
\hline Golpear ligeramente los dedos & Impaciencia \\
\hline $\begin{array}{l}\text { Sentarse con las manos agarrando la cabeza por } \\
\text { detrás }\end{array}$ & Superioridad \\
\hline $\begin{array}{l}\text { La cabeza descansando sobre las manos o mirar } \\
\text { hacia el piso }\end{array}$ & Aburrimiento \\
\hline Unir los tobillos & Aprensión \\
\hline Manos agarradas hacia la espalda & Furia, ira, frustración y aprensión \\
\hline Cruzar las piernas, balanceando ligeramente el pie & Aburrimiento \\
\hline Brazos cruzados a la altura del pecho & Actitud a la defensiva \\
\hline $\begin{array}{l}\text { Caminar con las manos en los bolsillos o con los } \\
\text { hombros encorvados }\end{array}$ & Abatimiento \\
\hline Manos en las mejillas & Evaluación \\
\hline Frotarse un ojo & Dudas \\
\hline Tocarse ligeramente la nariz & Mentir, dudar o rechazar algo \\
\hline
\end{tabular}

Nota: Elaborado con base en BFerrari Leonardo. Cómo conocer a las personas por su lenguaje corporal. 2008. 


\section{Tabla 3}

\section{Lenguaje corporal apropiado y significado}

\begin{tabular}{|c|c|}
\hline Lenguaje corporal & Significado \\
\hline Inclinar la cabeza & Interés \\
\hline Palma de la mano abierta & Sinceridad, franqueza e inocencia \\
\hline Caminar erguido & Confianza y seguridad en sí mismo \\
\hline Pararse con las manos en las caderas & Buena disposición para hacer algo \\
\hline Mirar directamente a los ojos de la otra & Estoy escuchando atentamente, me \\
\hline persona & interesa lo que quieras comunicar \\
\hline Mantener una distancia considerada de & Respeto tu espacio personal \\
\hline la otra persona & \\
\hline Sonría, sin exagerar & Confianza, alegría y buena disposición \\
\hline
\end{tabular}

Auditivo: La persona prefiere sus percepciones auditivas, depende de las palabras habladas para recoger su información y guiar su conducta. El alumno auditivo aprende con estímulos auditivos: diferentes tonos de voz, necesita repetición de instrucciones, utiliza la música para relacionar su aprendizaje, o actividades donde el audio tenga que utilizarse, alguna historia en audiolibro sería muy útil.

Kinestésico: Siente a través de la experiencia corporal, este incluye el olfato y el gusto. Aprende con sensaciones corporales: frío, calor, tocar otro alumno y relacionar sensaciones. Por ejemplo, alguna actividad donde haya juego de rol, donde actúe realizando algo aprendido en clase, haga una representación de algún tema en específico.

Además de tomar en cuenta estos estilos de aprendizaje, también es importante saber que algunas personas son diestras y otros zurdos, y aunque se utilicen ambas manos dependiendo de las actividades, existe una mano dominante que se utiliza cuando se requiere de precisión, fuerza o esmero.

De la misma manera, todos los que gocen de total salud utilizan todos los canales de comunicación, pero hay uno que es dominante y se emplea prioritariamente en las situaciones que requieren mayor esfuerzo, concentración o esmero.
Se recomienda observar con cuál mano escribe el alumno que se acerca a pedir ayuda, asesoría o explicación sobre algún tema, ya que de acuerdo a eso, se le debe hablar de la siguiente manera:

Diestros $=$ Hablar del lado del oído izquierdo. Zurdos = Hablar del lado del oído derecho.

Estima PNL que recibe y almacena información de dos maneras, o con dos hardwares muy distintos: los dos hemisferios del córtex cerebral, el izquierdo y el derecho, bastante desconectados entre sí, en el común de las personas. Hemisferio derecho: En lo físico, maneja el movimiento de la mano izquierda. Esta es la razón por la cual, si se intensifica el uso de esta mano, quienes son diestros, se esta promoviendo el empleo y desarrollo del hemisferio derecho. Hemisferio Izquierdo: Este hemisferio maneja el movimiento de la mano derecha. Aquí está lo programado, lo aprendido de la cultura.

Es por esto, que la información recibida de manera oral debe de ser comunicada de acuerdo a la mano con la cual la persona escribe, para que llegue por el canal correcto.

Recuerden en cuántas ocasiones le han explicado o dado una instrucción a alguna persona y que ponga cara de que no entendió y pide que se le repita la 
información, incluso repetida cantidad de veces, por muy insignificante que la información sea.

\section{Palabras y frases a utilizar}

Finalmente, recuerden «utilizar frases en positivo, evitemos todas aquellas palabras que indiquen negatividad" (Dilts,2003). Como se mencionaba al inicio de este artículo, evitar utilizar frases que ilustran lo que no se quiere, sino lo que queremos que suceda.

Cuando quieran que sus alumnos lleven cierto material al aula, o las fechas de entrega o exámenes las recuerden con facilidad, o comprendan una instrucción rápidamente ya sea de manera oral o escrita, pueden decir:

Recuerden que la fecha de entrega es el martes.

Traigan el material solicitado mañana.

Subrayen las ideas principales. Enlístenlas. Realicen un resumen con ellas.

Estudien para su examen.

También pueden «utilizar instrucciones donde la palabra mente esté presente» (Bandler, 1985), por ejemplo:

* Lean detenidamente las instrucciones.

* Subrayen atentamente.

* Hagan sus diapositivas cuidadosamente.

Con esta práctica también se puede lograr que las actividades las realicen de esa manera, la mente es la que recibe la instrucción directamente y lo hace como se le indique: detenidamente, atentamente 0 cuidadosamente.

Recuerden que la instrucción que se da, es lo que los alumnos van a hacer o realizar tanto en sus actividades de aula, trabajos, tareas y exámenes y que la palabra tiene poder. «La gente que se siente bien consigo misma produce resultados positivos» (Armas, Von Ruster, 2009).

\section{FUNCIONAMIENTO DEL CEREBRO Y SU RELACIÓN CON LA EDUCACIÓN}

Actualmente, los aportes de investigaciones realizadas en el ámbito de la psicología y de otras disciplinas han despertado un interés por conocer el funcionamiento del cerebro y diseñar experiencias organizadas y sistemáticas que faciliten su abordaje con modelos de intervención ( Heller, M. 1993).

Su entendimiento es básico para la aplicación y entendimiento de los diferentes métodos o sistemas que pueden mejorar y tener utilidad práctica de cualquier método de programación o sistema que se emplee. Se llama PNL por lo conocido del nombre, pero en realidad es el entendimiento del cerebro y su forma de aprovechamiento.

Debe partirse de la base en que el cerebro de los individuos tiene sus propias peculiaridades, no hay dos que sean exactamente iguales, y se catalogan de la siguiente manera:

\section{Cerebro Reptil}

Es el cerebro primario. En él se ubica la inteligencia básica, se posesionan los comportamientos y conductas que adquieren en la niñez y se repiten en la vida adulta. El uso de este cerebro proporciona la formación de hábitos mediante una acción repetida varias veces, hasta que se organiza y se estructura en «rutinas».

\section{Cerebro Neo-Córtex}

Este cerebro construye el pasado, el presente y el futuro de manera secuencial. Es un proceso que ocurre internamente y que permite fomentar y consolidar las capacidades de análisis. El hemisferio izquierdo se especializa en reconocer las partes que constituyen un conjunto, es lineal y secuencial. Pasa de un punto a otro de manera gradual, paso a paso. Procesa información verbal, codifica y decodifica el habla. Separa las partes que constituyen un todo; es como una computadora ya que tiene su propio lenguaje.

El hemisferio derecho combina partes para crear un todo, se dedica a la síntesis. Busca y construye relaciones entre partes separadas. Procesa simultáneamente en paralelo, es especialmente eficiente en el proceso visual y espacial (imágenes). Se especializa en relaciones no lineales, pareciera que es la fuente de la percepción creativa. Las palabras o figuras por sí solas no dicen nada, y si se juntan, se obtiene una comunicación más clara. Es como un caleidoscopio tiene un número casi infinito de variedades.

\section{Cerebro Límbico}

Procesa las emociones y los sentimientos. Constituye el sentir, las manifestaciones de las emociones humanas, de los afectos. Está relacionado con la memoria, atención, instintos sexuales, emociones, por ejemplo: placer, miedo, agresividad, personalidad y la conducta.

La PNL se puede emplear con sus diversos métodos en la educación, utilizando técnicas de enseñanza y 
comunicación para el incremento de capacidades y rendimiento en el aprendizaje, técnicas para «aprender a aprender».

\section{PNL y sus ventajas en la educación}

Se plantean objetivos a cumplir, seleccionan los contenidos que se relacionan con el tema, que actúa como organizador, interpretan y adaptan el currículo, creando situaciones ricas de aprendizaje, realizando evaluaciones iniciales en relación con los conocimientos previos y finales para evaluar los resultados y elaborar recapitulaciones.

El objetivo entre lo que los docentes quieren que los alumnos sepan y lo que los alumnos quieren aprender, surge de un ajuste de los dos propósitos, de una negociación.

Tenemos que tener en cuenta que gran parte de nuestros aprendizajes nos llegaron de forma intuitiva y sólo percibimos los resultados. Debemos crear un entorno que maximice las oportunidades del aprendizaje, un entorno abierto que permita explorar y experimentar sin peligro, en que las personas se puedan mostrar como son, donde los alumnos aprendan a asumir las responsabilidades de los aprendizajes, y se hagan más responsables de su desarrollo (Sánchez, 1991).

Para lograr un aprendizaje con éxito es en necesario en primer lugar conocer como son nuestros alumnos para valorar su estado anímico dispuesto para el aprendizaje y en base a ello implementar acciones que propicien un ambiente humano y óptimo para la enseñanza y el aprendizaje, un ambiente agradable que haga ala niño desear llegar a su aula dispuesto a adquirir los conocimientos, (González, 1996).

Según Isturiz y Carpio (1998), la PNL ofrece diferentes técnicas como herramientas de trabajo para que los alumnos las pongan en práctica y así tener más eficacia en el proceso de Enseñanza Aprendizaje: Las metáforas. Entre las cuales se incluyen relatos, analogías, palabras, ejemplos personales y chistes.

El rapport- Acompasar. Para la PNL se traduce en sintonía armonía concordancia con respecto a la relación interpersonal entre los individuos. La sintonía es un puente hacia la otra persona, lo que permite guiarlos a otra dirección estableciendo una buena relación en la PNL se llama compartir y dirigir. Una de las bases del rapport para que la comunicación llegue a ser excelente es que el docente debe colocarse en lugar del estudiante, sintonizando los ritmos del cuerpo del estudiante, respiración, velocidad, gestos, postura, macro y micro comportamiento (Sambrano, 1997).

Anclaje: Es un proceso mediante el cual, un estímulo externo se asocia con una conducta que se desea adquirir. Por ejemplo: tocarse la oreja cada vez que desea sentirse bien. Se unen las dos cosas, y luego el cerebro hace todo el trabajo. Anclar es asociar, entonces se puede aprender a juntar conductas de excelencia por medio de señales las cuales pueden ser palabras, gestos, sonidos, entre otras.

Cuando un alumno no ha prosperado en una determinada materia, el docente le puede aplicar la técnica del anclaje. A manera de ejemplo el alumno se visualizará triunfador y asociará la nota que quiere obtener con la materia (Carpio, 1996).

Reencuadre: Es una técnica que utiliza la PNL para modificar el marco de referencia, según la experiencia de vida que se tenga, es decir, aprender a ubicar el marco posible de referencia a través del recuerdo y la imaginación, con la intención de cambiar el significado de ese marco de referencia y en consecuencia también se cambia el estado emocional, las respuestas y las conductas de las personas (Bandler, Grinder, 1993).

Dentro del proceso de enseñanza-aprendizaje se puede aplicar la técnica del reencuadre concientizando al alumno quien tiene todos los recursos para cambiar de actitud en una actividad determinada, en la cual presente dificultades. Se puede lograr resaltando la parte positiva de esa actividad, el provecho que tiene, a fin de que el alumno cambie libremente el modo de realizar la actividad y así cambiará el significado traumático que tenía de ésta por un significado positivo (Isturiz y Carpio,1998).

\section{Conclusiones}

Los estilos de aprendizaje (canales de percepción sensoriales) que proponen Bandler y Grinder por medio de la aplicación de la PNL, nos hace más conscientes del lenguaje que utilizamos, nos ayuda a tener una percepción más clara de nuestros programas y de los demás, permitiéndonos entonces conocer los procesos mentales que usamos para codificar información al mismo tiempo que nuestra forma de pensar y actuar. Teniendo como resultado una comunicación eficaz con las demás personas. Aplicándolo a nuestro campo de trabajo, se mejoran notablemente las relaciones interpersonales y la manera en la que nos dirigimos a otros. 
Con PNL podemos conocernos mejor y por lo tanto optimizar nuestras capacidades para mejorar nuestras relaciones maestros-alumnos en cualquier ámbito, en especial en nuestro área: la educativa, y así cambiar técnicas y/o estrategias que ya no nos son útiles por las que son efectivas y que brindan resultados a corto plazo. Es cuestión de práctica. «No hay límites para lo que puedes lograr, pero necesitas empezar.» (Armas, Von Ruster, 2009).

El uso de las técnicas que proporciona la PNL, permite la comprensión y desarrollo del pensamiento innovador y de los procesos cognitivos y conductuales que se dan en el individuo, puesto que facilita la estimulación del cerebro Tri-uno (neo-cortex, límbico y reptil), que es un sistema de energía sin límites que da vida a cada ser humano. De esta manera, se logra un aprendizaje más efectivo, en la cual el alumno sienta más satisfacción, realice las actividades de manera más efectiva y sus pensamientos sean más organizados, con el propósito de tener un mejor aprovechamiento en los estudios.

En nuestro quehacer académico, hemos observado cómo las relaciones con nuestros grupos han mejorado notablemente a raíz de la implementación de PNL en el aula. Independientemente del idioma, las instrucciones o indicaciones ya no tienen que repetirse varias veces como en el pasado. Recuerdan con facilidad lo explicado en clase y lo comprenden desde la primera vez que se expone además de que los alumnos tienen la confianza, porque la sienten, de acercarse a preguntar sin temor. Participan inclusive los más tímidos y retraídos, en actividades que normalmente no lo hacen, alumnos, que es sabido por otros compañeros maestros, tienen actitudes apáticas o no colaborativas.

Aplicando PNL, no hay margen para estas actitudes, nos enseña a anticipar este tipo de situaciones y buscar la estrategia adecuada para abordarlos e involucrarlos.

Incorporar la PNL con la intención de hacer más eficaz el proceso enseñanza - aprendizaje en la educación, sobre todo en la D.A.C.E.A., es de gran importancia, porque le facilita al alumno actuar de forma integral, es decir, que no solo se pretende saturar el cerebro de conocimientos, sino de formar alumnos con una nueva mentalidad ante la vida y sus estudios.

Formar, quiere decir transmitir de generación en generación aquellos valores espirituales que dan a la vida un gran significado y esto se logra a través de las palabras que se vuelven palpables y visibles en la vida de cada individuo.

Finalmente PNL es amable con cualquier edad. Para los jóvenes hay técnicas para que descubran cómo lograr sus objetivos y aprender a tomar mejores decisiones. $Y$ para los adultos mayores hay técnicas para lograr una mejor comunicación con los jóvenes.

«Nunca es tarde para el cambio, la mente puede cambiar y crear nuevos caminos si se lo permitimos" (Bandler, 1985).

\section{REFERENCIAS}

Armas, L., y Von, C. (2009). Metaforeando. México: Endira.

Bavister, S., y Vickers, A. (2005). Programación Neurolingüística (PNL), las claves para una comunicación más efectiva. España: Amat.

Bandler, R. (1985). Use su cabeza para variar. México: Cuatro Vientos.

Bandler, R., y Grinder, J. (1993). Trance Fórmate. España: Gaia.

Burón, J. (1996). Enseñar a aprender: introducción a la metacognición. Bilbao: Mensajero.
Carpio, M. (1996). Anclajes y reencuadres: recursos para un aprendizaje. Revista de investigación.

Instituto Pedagógico de Miranda «J.M. Siso Martínez». Volumen 4. Caracas.

Dilts, R. (2003). El poder de la palabra: La magia del cambio de creencias a través de la conversación. España: Urano.

Ferrari, L. (2008). ¿Cómo conocer a las personas por su lenguaje corporal? Argentina: Ciao.

Glouberman, D. (1991). Imaginar es poder. España: Urano.González, L. (1996). PNL Comunicación y Diálogo. Editorial Font. México: Trillas. 
Griinder, J., y Bandler, R. (2000). De sapos a príncipes. México: Cuatro Vientos.

Heller, M. (1993). El arte de enseñar con todo el cerebro. Caracas: Biósfera.

Istúriz, N., y Carpio, M. (1998). ¡Mira! ¡Escucha! y contáctate con la PNL. Caracas: Biósfera.

Mohl, A. (2006). El aprendiz de brujo. Málaga, España: Sirio.

O'connor, J., y Mcdermott, I. (1997). El lenguaje corporal. México: Plaza \& Janes.

O’Connor, J. y Seymour, J. (1992). Introducción a la programación neuro-lingüística. Barcelona, España: Ediciones Urano.

Sambrano, J. (1997). PNL para todos. Caracas: Alfadil.

Sambrano, J. (1997). El modelo de la excelencia. Recuperado de www.books.google.com.mx/ books?isbn=9803540424

Sánchez, M. (1991). Desarrollo de habilidades del pensamiento. México: Trillas. México.

Sin referencia (2012, Marzo 10). Qué es programación neurolingüística. Recuperado de http:// www.estrategiaspnl.com/pnl.phtml

Skinner, B. (1973). Tecnología de la enseñanza. Barcelona, España: Trillas.

Vázquez, A. (2008, Noviembre). Estilos de Aprendizaje y PNL. Recuperado de www.slideshare.net/no.../ estilos-de-aprendizaje-y-pnl-presentation.

Verlee, L. (1986). Aprender con todo el cerebro. Barcelona, España: Martínez Roca. 